Available online at GSC Online Press Directory

GSC Biological and Pharmaceutical Sciences

e-ISSN: 2581-3250, CODEN (USA): GBPSC2

Journal homepage: https://www.gsconlinepress.com/journals/gscbps

(REVIEW ARTICLE)

\title{
Vitamin supplements in the Era of SARS-Cov2 pandemic
}

\author{
Carella Angelo Michele ${ }^{1,}{ }^{*}$, Benvenuto Angelo ${ }^{1}$, Lagattolla Valeria ${ }^{2}$, Marinelli Teresa ${ }^{1}$, De Luca Pasquale ${ }^{1}$, \\ Ciavarrella Giuseppe ${ }^{1}$, Modola Giovanni ${ }^{1}$, Di Pumpo Michele ${ }^{1}$, Ponziano Ernestina ${ }^{3}$ and Benvenuto Mario ${ }^{4}$ \\ ${ }^{1}$ Department of Internal Medicine, "T. Masselli-Mascia" Hospital, 71016 San Severo (Foggia), Italy. \\ 2 Department of Endocrinology, Metabolic Diseases and Clinical Nutrition, "Perrino" Hospital, 72100 Brindisi, Italy; \\ National Board Member of the Italian Association of Dietetic and Clinical Nutrition (ADI). \\ ${ }^{3}$ Biochemical Laboratory of Territorial Assistance Unit (PTA), 71017 Torremaggiore (Foggia), Italy. \\ 4 Department of Medical Genetics, IRCCS “Casa Sollievo della Sofferenza” Hospital, 71013 San Giovanni Rotondo (Foggia), \\ Italy.
}

Publication history: Received on 27 April 2020; revised on 03 May 2020; accepted on 04 May 2020

Article DOI: https://doi.org/10.30574/gscbps.2020.11.2.0114

\begin{abstract}
Recently, the rapid and extensive spread of a novel human RNA betacoronavirus, known as severe acute respiratory syndrome coronavirus 2 (SARS-CoV-2), is causing a worldwide public health emergency, originated in Wuhan, China. The disease caused by this new coronavirus, called "COVID-19", is very contagious. Although most of infected subjects are asymptomatic or present with mild flu-like symptoms, the rapid spread of the virus has resulted in a significant amount of serious interstitial pneumonia that may quickly develop into severe acute respiratory distress syndrome (ARDS), septic shock, sepsis-induced coagulopathy and fatal multiorgan dysfunction. Hence, the unabated spread of the disease demands an immediate need to explore all the plausible therapeutic and prophylactic strategies for reducing the high morbidity and mortality of this infection. At present, there is no vaccine or certainly effective antiviral treatment for human SARS-Cov-2 and the mainstay of clinical management is prevalently symptomatic treatment combined with a panel of drugs having variable and uncertain efficacy. Unfortunately, no many drugs have yet been approved to treat human SARS-Cov-2 infection and many agents are administered in off label route; several options are being studied to control or prevent clinical manifestations of this infection, including monoclonal antibodies, antiviral and anti-cytokine agents, antibiotics, and other drugs. Given that several vitamins are known to have antimicrobial properties and immunomodulatory activity, a potential role of vitamins in the COVID-19 treatment was investigated.
\end{abstract}

Keywords: SARS-CoV-2 infection; COVID-19; Vitamin supplements

\section{Introduction}

In these months, the diffusion of a novel human RNA betacoronavirus, known as severe acute respiratory syndrome coronavirus 2 (SARS-CoV-2), is causing a worldwide public health emergency, originated in Wuhan, China. The disease caused by this new coronavirus is commonly called "COVID-19", which is the acronym of "coronavirus disease 2019" [1].

Although most of infected subjects by SARS-Cov-2 are asymptomatic or present with mild flu-like symptoms, such as fever, cough, arthromyalgias and fatigue [2], but also diarrhea, ageusia and anosmia [3,4] , the rapid spread of the virus has resulted in a significant amount of serious interstitial pneumonia that may quickly develop into severe acute respiratory distress syndrome (ARDS), septic shock and fatal multiorgan dysfunction that are the most severe clinical manifestations of SARS-Cov-2 infection. The severe progression of COVID-19 seems to result from the so called "cytokine storm", due to massive SARS-Cov-2-induced release of pro-inflammatory mediators and cytokines,

\footnotetext{
* Corresponding author: Carella Angelo Michele e-mail: mic.carella@virgilio.it phone: +390882200478
} 
particularly interleukin-1 (IL-1), interleukin-6 (IL-6) and tumor necrosis factor- $\alpha$ (TNF $\alpha$ ), linked to viral replication and leading to cytokine release syndrome-like [5]. "Sepsis-induced coagulopathy" [6,7] may be a potential serious complication of SARS-Cov-2 pneumonia and this event is associated with poor prognosis [8,9]. Acute pulmonary embolism [10,11], microthrombotic occlusion of small pulmonary vessels [12,13] and disseminated intravascular coagulation [14] have been reported in critical patient with COVID-19.

Hence, the unabated spread of COVID-19 demands an immediate need to explore all the plausible therapeutic and prophylactic strategies for reducing the high morbidity and mortality of this infection. At present, there is no vaccine or certainly effective antiviral treatment for human SARS-Cov-2 and the mainstay of clinical management is prevalently symptomatic treatment combined with a panel of drugs having variable and uncertain efficacy [15].

Originally, the therapeutic approach was to repurpose some drugs already used to treat two previous infections caused by other human coronaviruses as severe acute respiratory syndrome (SARS) [16] and Middle East respiratory syndrome (MERS), taking advantage also from chinese experience data [17]. At the moment, a multitude of compounds are under investigation for the treatment of this emerging disease, including vaccines, monoclonal antibodies, antiviral and anticytokine agents, antibiotics and other drugs. Unfortunately, no many drugs have yet been approved to treat human SARS-Cov-2 infection and many agents are administered in off label route. Several options are being studied to control or prevent clinical manifestations of the infection and many studies and clinical trials have been started and are currently ongoing in all Countries affected by this severe pandemic.

Despite some vitamins are known to have antimicrobial properties and immunomodulatory activity, at the moment poor relevance regarding a potential role of vitamins supplementation in the therapeutic armamentarium against SarsCov-2 we have found. In this narrative review any benefits from vitamins in the COVID-19 treatment was investigated.

\section{Discussion}

We following provide and discuss data from our research in evaluating evidence regarding a potential role of vitamins and their supplementation in patients with SARS-Cov-2 infection.

\subsection{Vitamin C}

There is evidence that patients with acute infections, in particular critically ill patients [18], have low circulating levels of Vitamin C, due prevalently to metabolic consumption $[19,20]$ and several experimental and clinical studies have proved antimicrobial properties and antiviral effects of Vitamin C [21-24].

It has been shown, in vitro and in vivo studies that Vitamin C might reduce the risk of infections and exerts immunomodulatory functions, particularly in high concentrations and in form of dehydroascorbic acid [22, 23, 25-29]. Vitamin $C$ may have beneficial effects in patients with viral infections by increasing $\alpha / \beta$ interferon production and downregulating pro-inflammatory cytokines production [30,31]. Additionally, Vitamin $C$ is a powerful antioxidant compound against free radicals and reactive oxygen species [32,33]. There is evidence that Vitamin $\mathrm{C}$ infusion may improve sepsis and sepsis-induced multiorgan dysfunction and reduce mortality in patients with sepsis and severe acute respiratory failure [18,21,22]; improvement of lung inflammation, induced by influenza A virus/H1N1, was also reported in patients taking Vitamin C [34]. Past controlled trials have reported significantly lower incidence of pneumonia in vitamin C-supplemented individuals, suggesting that Vitamin $\mathrm{C}$ might prevent the susceptibility to lower respiratory tract infections under certain conditions [35]. Results from other new larger trials are awaited and further data on severe respiratory viral infection are needed.

Fruit and vegetables as citrus fruits, kiwi, mango, strawberries, papaya, tomatoes, green leafy vegetables, and broccoli are natural sources of Vitamin C [33] and recommended daily allowance (RDA) of Vitamin C is 75 and 90 mg for women and men respectively [33,36,37]; additional supplement of $35 \mathrm{mg}$ daily is suggested in smokers, given that these subjects have lower Vitamin C status than nonsmokers [33]. Other evidence indicates that the RDA for Vitamin C could be too low and suggests that $200 \mathrm{mg}$ daily is the optimum intake of Vitamin C for adult population, particularly during stress conditions [38].

Vitamin C is generally safe and well tolerated, even in large doses; gastrointestinal disorders were observed in some individuals taking Vitamin $\mathrm{C}$ at dosage higher than $2 \mathrm{~g}$ daily and increased risk of kidney stones was also reported, due to high amounts of Vitamin C intake [33]. Despite there is no sure evidence on benefit of Vitamin C in patients with SARS-Cov-2 infection, waiting for the results of further studies recently initiated [39], we believe that nutritional Vitamin C supplementation is advisable and Vitamin C infusion should be evaluated in hospitalized patients. 


\subsection{Vitamin D}

In addition to its role in maintaining bone integrity, Vitamin $\mathrm{D}$ also stimulates the maturation of many cells, including immune cells. It is well known that Vitamin D receptors are expressed on immune cells, as B cells, T cells, and antigenpresenting cells and it has been proved as Vitamin D has the capability to modulate innate and adaptive immune responses; moreover, there is evidence that Vitamin D deficiency is associated with increased susceptibility to common infections, like sepsis, pneumonia, influenza and other infectious diseases [40,41]. Data from a recent systematic review and meta-analysis [42] regarding the effect of Vitamin D-calcium co-supplementation on inflammatory biomarkers confirm beneficial effect on plasma levels of C-reactive protein while such a beneficial effect was not observed for IL-6 and TNF- $\alpha$ concentrations.

Vitamin D is a fat-soluble vitamin naturally contained in very few foods (fatty fish, fish liver oils, beef liver, cheese and eggs) and available as a dietary supplement; it is also endogenously produced when ultraviolet rays from sunlight strike the skin. In nutritional supplements and fortified foods, Vitamin D is available in two forms, D2 (Ergocalciferol) and D3 (Cholecalciferol) and current RDA for Vitamin D is $600 \mathrm{IU}(15 \mu \mathrm{g}$ ) daily for adults up to 70 years of age and $800 \mathrm{IU}$ $(20 \mu \mathrm{g})$ daily for those over 70 years [43,44]. A high number of healthy adults have been reported to have low levels of Vitamin D, mostly at the end of the winter season [45]; in addition, housebound or institutionalized people may have Vitamin D deficiency as well as many elderly people, which have limited exposure to sunlight [46].

Since the hallmark of Vitamin D intoxication is hypercalcemia and its sequelae, which are associated with a rise in serum 25-hydroxyvitamin D levels, calcemia and 25-hydroxyvitamin D plasma levels monitoring is recommendable particularly in long-term Calciferol-treated patients. Vitamin D intoxication generally presents with non-specific symptoms that may vary and often include anorexia, weight loss, polyuria, and heart arrhythmias. The condition eventually leads to vascular and tissue calcification with subsequent renal and cardiovascular damage $[47,48]$.

We have not found strong evidence regarding Vitamin D efficacy in COVID-19 patients, however, given that adult individuals are at increased risk to develop Vitamin D deficiency (serum levels $<30 \mathrm{nmol} / \mathrm{L}$ ), oral supplementation with prophylactic dosage of Vitamin D would not be inadvisable.

\subsection{Vitamin E}

Vitamin E is a group of eight lipidsoluble compounds, known as chromanols that are widely distributed in the plant kingdom and alpha-tocopherol has the highest bioavailability in the human body [49].

The antioxidant/radical scavenging activity of Vitamin E is well recognized as well as other non-antioxidant functions such as its role in cardiovascular diseases and cancer prevention and its protective functions against neurodegenerative diseases, as Parkinson's and Alzheimer's [50-53]. Apart from the antioxidant function, necessary to maintain membrane cells integrity and bioactivity, anti-inflammatory effects and immunomodulatory function of Vitamin E were also described [50,54]. In particular, animal and human studies have shown that Vitamin E deficiency causes impairment of humoral and $\mathrm{T}$ cell-mediated immune functions that may be restored by vitamin E repletion [54-61]. There is also evidence that Vitamin E supplementation may reduce inflammatory cytokines production and improve $\mathrm{T}$ cells proliferation through directly impacting membrane integrity, signal transduction and T cells differentiation [59,62-65]; moreover, Vitamin E supplementation improves leukocyte phagocytic capacity [60,66-69] and neutrophils and NK cells functions. Data from other studies show that Vitamin E supplementation was associated with 63\% lower rate of rehospitalization among older adults previously hospitalized with pneumonia [70] and lower incidence and shorter duration of upper respiratory infection in elderly nursing home residents (>65 years) [71].

Yet, other studies have not confirmed a strong efficacy of Vitamin E supplementation on immunological and infectious state of participants [72-74]. The discordant results on effectiveness of Vitamin E interventions may be attributed to differences in studies population and in Vitamin E administration; moreover, polymorphisms in Vitamin E-metabolism related genes, including apolipoprotein E, lipoprotein lipase, scavenger receptors and alpha-tocopherol transfer protein may influence the effect of Vitamin E supplementation. Genetic background has been identified as an important nonmodifiable factor in both the bioavailability and cellular activity of Vitamin E [75].

The human diet contains different Vitamin E-related molecules and, fortunately, Vitamin E is widespread in nearly all foods and as a result most people are not at risk of deficiency, unless nutrient absorption is impaired. The cause of Vitamin E deficiency, characterized by peripheral neuropathy and ataxia, is usually fat malabsorption or genetic abnormalities in lipoprotein metabolism [76]. 
Seeds (wheat germ, sunflower seeds) and nuts (almonds, hazelnuts, pine nuts, peanuts and others) are among the best sources of Vitamin E, but also many animal-based foods (seashell, salmon, trout) are good sources of Vitamin E as well as vegetables (extra-virgin olive oil, red sweet pepper, beet greens, broccoli) and fruit (avocado, mango, kiwifruit) [7779].

In healthy individuals, the RDA of Vitamin $\mathrm{E}$ is $15 \mathrm{mg}$ daily of alpha-tocopherol; this is equivalent to 22 IU of natural source Vitamin E per day, or 33 IU from synthetic sources. Although deficiency is rare, Vitamin E supplementation above current dietary recommendations has been shown to enhance the function of the immune system and affects host susceptibility to infectious diseases, such as respiratory infections, reducing risk of infection or mitigating several viral and bacteria, particularly in older individuals. Vitamin E may enhance digitalis and insulin effects, then caution is recommended in patients on digitalis and insulin treatment. Moreover, prolonged use of high doses of Vitamin E ( $>560$ $\mathrm{mg} / 800$ IU daily) may be associated with increased bleeding tendency in patients with Vitamin K deficiency; increased risk of bleeding must be evaluate in patients treated with anticoagulant drugs. In patients taking high doses of Vitamin E gastrointestinal disorders, as nausea, diarrhea, flatulence, abdominal pain, and other side effects as asthenia, headache, blurred vision and dermatitis were reported $[80,81]$. Despite antioxidant and anti-inflammatory properties of Vitamin E are well demonstrated, as well as its immunomodulatory and antimicrobial activity, at the moment there are no significant evidence regarding the efficacy of Vitamin E supplements in patients with SARS-Cov- 2 infections.

\subsection{Vitamin A}

Vitamin A is an unsaturated 20 carbon cyclic alcohol, also known as Retinol $[82,83]$, that is part of a broad group of substances called Retinoids [84] including Retinaldehyde and Retinoic acid [85-87].

Vitamin A exerts many functions and metabolic effects via its interrelationship with hormones such as thyroid, insulin, and corticosteroids, and it is essential in a lot of physiologic processes, including epithelial differentiation, bone development and growth, reproduction, embryogenesis, antioxidant, hematopoiesis, brain development and vision [8893]. Vitamin $A$ is also essential for modulating and proper functioning of the immune system [94-96], particularly by regulating T cell-dependent responses [97-99]. Moreover, it has been observed as Vitamin A regulates cytokine expression in respiratory epithelial and macrophage cell lines by modulating IL-6 expression, so an essential role of Vitamin A in healthy immune response to respiratory pathogens it has been hypothesized. $[100,101]$. There is evidence that Vitamin A deficiency is more common during infection [98] and, especially in childhood, increases the morbidity and mortality risk from gastrointestinal and pulmonary tracts infections [102-104]. In addition, it has been reported that Vitamin A supplementation may reduce severe morbidity and mortality from infectious diseases such as measles, measles-related pneumonia, human immunodeficiency virus infection, diarrheal disease and malaria [105-108].

Vitamin A supplements are indicated for prevention or treatment of Vitamin A deficiency states. Vitamin A deficiency may occur as a result of inadequate nutrition or intestinal malabsorption but does not occur in healthy individual receiving an adequate balanced diet. For prophylaxis of Vitamin A deficiency, dietary improvement, rather than supplementation, is advisable [109,110]. The RDA for Vitamin A (Retinol Activity Equivalents) is 300 to $700 \mu \mathrm{g}$ for children and approximately 700 to $900 \mu \mathrm{g}$ for adults, amounts that may be provided by a normal diet [36,111]. Some foods of animal origin (liver, fish liver oil, eggs, milk and butter) mainly contain Retinol [112]; vegetables and fruit (carrots, spinach, broccoli, peas, tomato, sweet potato, extra-virgin olive oil, apricots, peach) mainly contain carotenoids [113], in particular $\beta$-carotene [83], which are converted into Retinol in the liver.

Vitamin A at doses not exceeding the physiologic requirement is usually nontoxic; headache, nausea, vomiting, and irritability have been observed after excessive intake of Vitamin A. Moreover, high doses of Vitamin A can be toxic, leading to more serious symptoms as well as liver injury, jaundice, enlargement of the liver and spleen, portal hypertension and cirrhosis; excess of Vitamin A during pregnancy has been linked to birth defects. Too much Vitamin A can be harmful and Vitamin A toxicity can be critical and even result in death $[114,115]$.

When considering Vitamin A supplementation, the potential benefits must be weighed against the risk of harm; the evidence for supplementation with Vitamin A is currently limited to expert opinion and is not backed up by rigorous trials. Further studies and clinical trials are needed to establish effective and safety of Vitamin A supplementation [110].

Apart from poor animal studies [116,117], searching for Vitamin A and SARS-Cov-2 and COVID-19 we have not found significant items, then, at the moment, we do not recommend Vitamin A supplementation in these patients. However, Vitamin A could be a promising option for the treatment of this novel coronavirus and the prevention of lung infection. 


\subsection{Group B Vitamins}

B Vitamins have various functions but they act predominantly as coenzymes involved in cell energy metabolism and organic molecules synthesis [118-120]. In addition to these functions, they also play an essential role for the immune system that is composed of high turnover cells [121]; in particular Folic acid, Vitamin B12 (Cobalamin) and Vitamin B6 (Pyridoxine) exert direct regulatory effects on the immune response [122].

For instance, in animal and human studies Vitamin B6 and B12 have been shown to play an important role in the cytotoxic immune response mediated by Natural Killer and CD8+ T cells [123-125] and their deficiency was correlated to impairment of Natural Killer cell activity and B lymphocytes reduction due to their inhibited proliferation $[124,126,127]$. In addition, deficiency in Vitamin B6 leads to a lower activity of thymus in rats $[127,128]$ while in the elderly it was associated with impaired T helper cell functions and IL-2 production [129]. An inverse relationship between Vitamin B6 and some inflammatory markers as C-reactive protein and IL-6 receptor was also observed $[130,131]$.

Folate deficiency also causes negative effects on some immune functions [132,133]; moreover, since the metabolism of Folate and Vitamin B12 is closely related [134], the balance between these vitamins is also essential for the immune response so much that Natural Killer cell activity was found impaired by excessive levels of unmetabolized free Folic acid [135].

Suboptimal status of one or several B Vitamins might be found particularly in elderly individuals; in the case of Vitamin B12, the high prevalence of atrophic gastritis in this population results in disturbed absorption of Cobalamin and also of Vitamin B6 [136-140]. Although insufficient supply of Folate is common in many population groups and causes many health problems $[138,140]$, the reported potentially negative effects of high Folate intake due to excessive supplementation or consumption of fortified foods should be considered. This is especially relevant in light of the balance between Vitamin B12 and Folate.

As foods of animal origin are the only natural source of Vitamin B12, deficiency may occur in subjects avoiding these foods or consuming low amounts like vegetarians or vegans or low-income populations especially in developing countries [141,142].

Although there are some evidence also regarding potential antimicrobial of Vitamin B2 (Riboflavin) [143] and B3 (Nicotinamide) [144] as well as weakening host immune response by B Vitamins shortage, we have not found strongly significant data to advise group B Vitamins supplementation in SARS-Cov-2 infected patients to enhance their immune response.

\subsection{Vitamin $K$}

Vitamin $\mathrm{K}$ is essential for the synthesis of hepatic blood coagulation factors, as factors II (prothrombin), VII, IX, and X $[145,146]$ and it is well known that some anticoagulant drugs [147], employed in anti-thrombotic prophylaxis and treatment, act by inhibiting Vitamin K [148,149].

Green leafy vegetables and others as Brussels sprouts, broccoli, cauliflower and cabbage are rich dietary sources of Vitamin K; instead fish, liver, meat, eggs and cereals contain smaller amounts [150] and currently adequate intakes of Vitamin K are 90 and $120 \mu$ g daily for women and men, respectively [150,151].

Given that acute pulmonary embolism $[10,11]$ and microthrombotic occlusion of small pulmonary vessels $[12,13]$ may complicate the SARS-Cov-2 infection and were reported in critical patient with COVID-19, Vitamin K supplementation seems irrational and is not indicate in these patients. Moreover we have not found sufficient evidence proving the opposite.

\section{Conclusion}

SARS-CoV-2 infection is causing a worldwide public health emergency and several options are being studied to control and prevent clinical manifestations of this infection; many studies and clinical trials have been started and are currently ongoing in all Countries involved in this severe pandemic.

At the moment, several compounds are under investigation for the treatment of this emerging disease, but it seems that poor relevance has been devoted to the nutritional aspects in these patients. We have evaluated the evidence regarding a potential role of vitamins in the therapeutic armamentarium for patients with SARS-Cov-2 infection: the most 
significant data concern Vitamin C and Vitamin D so we suggest the patients to modify their nutritional choices by preferring foods richer in these vitamins; however Vitamin $\mathrm{C}$ and Vitamin D supplementation should be consider at least in selected patients. About Vitamins A and Vitamin E we found weaker evidence as well as poor data regarding group B Vitamins, while we consider Vitamin K supplements harmful and not rational. We hope scientific community will quickly conduct further studies to provide more certainties and indications in this field.

\section{Compliance with ethical standards}

\section{Disclosure of conflict of interest}

The Authors declare no conflict of interest.

\section{References}

[1] Wang C, Horby PW, Hayden FG and Gao GF. (2020). A novel coronavirus outbreak of global health concern. Lancet, published online Jan 24.

[2] Chaolin H, Yeming W. Xingwang L, Ren L, Zhao J, Hu Y, Zhang L, Fan G, Xu J, Gu X, Cheng Z, Yu T, Xia J, Wei Y, Wu W, Xie X, Yin W, Li H, Liu M0, Xiao Y, Gao H1, Guo L, Xie J, Wang G, Jiang R, Gao Z, Jin Q, Wang J and Cao B. (2019). Clinical features of patients infected with 2019 novel coronavirus in Wuhan, China. Lancet, 395, 497-506.

[3] Vaira LA, Salzano G, Deiana G and De Riu G. (2020). Anosmia and ageusia: common findings in COVID-19 patients. Laryngoscope.

[4] Gane SB, Kelly C and Hopkins C. (2020). Isolated sudden onset anosmia in COVID-19 infection. A novel syndrome? Rhinology.

[5] Zhang C, Wu Z, Li JW, Zhao H and Wang GQ. (2020). The cytokine release syndrome (CRS) of severe COVID19 and Interleukin-6 receptor (IL-6R) antagonist Tocilizumab may be the key to reduce the mortality. International Journal of Antimicrobial Agents, 105954.

[6] Iba T, Levy JH, Warkentin TE, Thachil J, van der Poll T and Levi M. (2019). Diagnosis and management of sepsisinduced coagulopathy and disseminated intravascular coagulation. Journal of Thrombosis and Haemostasis, 17(11), 1989-1994.

[7] Levi M and van der Poll T. (2017). Coagulation and sepsis. Thrombosis Research, 149, 38-44.

[8] Tang N, Li D, Wang X and Sun Z. (2020). Abnormal Coagulation parameters are associated with poor prognosis in patients with novel coronavirus pneumonia. Journal of Thrombosis and Haemostasis, 18(4), 844-847.

[9] Klok FA, Kruip MJHA, van der Meer NJM, Arbous MS, Gommers DAMPJ, Kant KM, Kaptein FHJ, van Paassen J, Stals MAM, Huisman MV and Endeman H. (2020). Incidence of thrombotic complications in critically ill ICU patients with COVID-19. Thrombosis Research, S0049-3848(20)30120-1.

[10] Rotzinger DC, Beigelman-Aubry C, von Garnier C and Quanadli SD. (2020). Pulmonary embolism in patients with COVID-19: Time to change the paradigm of computed tomography. Thrombosis Research 190, P58-59.

[11] Cui S, Chen S, Li X, Liu S and Wang F.J (2020). Prevalence of venous thromboembolism in patients with severe novel coronavirus pneumonia. Journal of Thrombosis and Haemostasis.

[12] Luo W, Yu H, Gou J, Li X, Sun Y, Li J and Liu L. (2020). Clinical Pathology of Critical Patient with Novel Coronavirus Pneumonia (COVID-19). Preprints, 2020020407.

[13] Huang C, Wang Y, Li X, Ren L, Zhao J, Hu Y, Zhang L, Fan G, Xu J, Gu X, Cheng Z, Yu T, Xia J, Wei Y, Wu W, Xie X, Yin W, Li H, Liu M, Xiao Y, Gao H, Guo L, Xie J, Wang G, Jiang R, Gao Z, Jin Q, Wang J and Cao B. (2020). Clinical features of patients infected with 2019 novel coronavirus in Wuhan, China. Lancet, 395(10223), 497-506.

[14] Lillicrap D. (2020). Disseminated intravascular coagulation in patients with 2019-nCoV pneumonia. Journal of Thrombosis and Haemostasis, 18(4), 786-787.

[15] Zumla A, Hui DS, Azhar EI, Memish ZA and Maeurer M. (2020). Reducing mortality from 2019-nCoV: host-directed therapies should be an option. Lancet, 395, e35-e36.

[16] Tong TR. (2009). Drug targets in severe acute respiratory syndrome (SARS) virus and other coronavirus infections. Infectious Disorders - Drug Targets, 9(2), 223-45. 
[17] Choudhry H, Bakhrebah MA, Abdulaal WH, Zamzami MA, Baothman OA, Hassan MA, Zeyadi M, Helmi N, Alzahrani F, Ali A, Zakaria MK, Kamal MA, Warsi MK, Ahmed F, Rasool M and Jamal MS. (2019). Middle East respiratory syndrome: pathogenesis and therapeutic developments. Future Virolology, 14(4), 237-246.

[18] Carr AC, Rosengrave PC, Bayer S, Chambers S, Mehrtens J and Shaw GM. (2017). Hypovitaminosis C and vitamin C deficiency in critically ill patients despite recommended enteral and parenteral intakes. Critical Care, 21, 300.

[19] Hemilä H. (2017). Vitamin C and Infections. Nutrients, 9(4), 339.

[20] Marik PE. (2018). Vitamin C for the treatment of sepsis: the scientific rationale. Pharmacology \& Therapeutics, 189, 63-70.

[21] Fowler AA 3rd, Truwit JD, Hite RD, Morris PE, DeWilde C, Priday A, Fisher B, Thacker LR 2nd, Natarajan R, Brophy DF, Sculthorpe R, Nanchal R, Syed A, Sturgill J, Martin GS, Sevransky J, Kashiouris M, Hamman S, Egan KF, Hastings A, Spencer W, Tench S, Mehkri O, Bindas J, Duggal A, Graf J, Zellner S, Yanny L, McPolin C, Hollrith T, Kramer D, Ojielo C, Damm T, Cassity E, Wieliczko A and Halquist M. (2019). Effect of vitamin c infusion on organ failure and biomarkers of inflammation and vascular injury in patients with sepsis and severe acute respiratory failure: the CITRIS-ALI Randomized clinical trial. Journal of the American Medical Association, 322, $1261-1270$.

[22] Gao YL, Lu B, Zhai JH, Liu YC, Qi HX, Yao Y, Chai YF and Shou ST. (2017). The Parenteral Vitamin C Improves Sepsis and Sepsis-Induced Multiple Organ Dysfunction Syndrome via Preventing Cellular Immunosuppression. Mediators of Inflammation, 4024672.

[23] While LA, Freeman CY, Forrester BD and Chappell WA. (1986). In vitro effect of ascorbic acid on infectivity of herpesviruses and paramyxoviruses. Journal of Clinical Microbiology, 24, 527-531.

[24] Furuya A, Uozaki M, Yamasaki H, Arakawa T, Arita M and Koyama AH. (2008). Antiviral effects of ascorbic and dehydroascorbic acids in vitro. International Journal of Molecular Medicine, 22(4), 541-5.

[25] Sorice A, Guerriero E, Capone F, Colonna G, Castello G and Costantini S. (2014). Ascorbic acid: its role in immune system and chronic inflammation diseases. Mini Reviews in Medical Chemistry, 14(5), 444-52.

[26] Huijskens MJ , Walczak M, Sarkar S, Atrafi F, Senden-Gijsbers BL, Tilanus MG, Bos G M, Wieten L and Germeraad WT. (2015). Ascorbic acid promotes proliferation of natural killer cell populations in culture systems applicable for natural killer cell therapy. Cytotherapy, 17(5), 613-20.

[27] Manning J, Mitchell B, Appadurai DA, Shakya A, Pierce LJ, Wang H, Nganga V, Swanson PC, May JM, Tantin D and Spangrude GJ. (2013). Vitamin C promotes maturation of T-cells. Antioxidant Redox Signaling, 19(17), 205467.

[28] Webb AL and Villamor E. (2007). Update: effects of antioxidant and non-antioxidant vitamin supplementation on immune function. Nutrition Reviews, 65(5), 181-217.

[29] Gorkom GNY, Klein Wolterink RGJ, Van Elssen C, Wieten L, Germeraad WTV and Bos GMJ. (2018). Influence of Vitamin C on Lymphocytes: An Overview. Antioxidants, 7(3), pii: E41.

[30] Carr AC. (2017). Vitamin C and Immune Function. Nutrients, 9, 1211.

[31] Kim Y, Kim H, Bae S, Choi J, Lim SY, Lee N, Kong JM, Hwang YI, Kang JS and Lee WJ. (2013). Vitamin C is an essential factor on the anti-viral immune response through the production of interferon-alpha/beta at the initial stage of influenza A virus (H3N2) infection. Immune Network, 13, 70-74.

[32] Tveden-Nyborg P and Lykkesfeldt J. (2013). Does vitamin C deficiency increase lifestyle-associated vascular disease progression? Evidence based on experimental and clinical studies. Antioxidant \& Redox Signaling, 19(17), 2084-104.

[33] Lykkesfeldt J, Michels AJ and Frei B. (2014). Vitamin C. Advances in Nutrition, 5(1), 16-8.

[34] Kim H, Jang M, Kim Y, Choi J, Jeon J, Kim J, Hwang YI, Kang JS and Lee WJ. (2016). Red ginseng and vitamin C increase immune cell activity and decrease lung inflammation induced by influenza A virus/H1N1 infection. Journal of Pharmacy and Pharmacology, 68(3), 406-20.

[35] Hemila H. (1997). Vitamin C intake and susceptibility to pneumonia. The Pediatric Infectious Disease Jornal, 16, 836-837.

[36] Institute of Medicine (US). (2000). Panel on Dietary Antioxidants and Related Compounds. Dietary Reference Intakes for Vitamin C, Vitamin E, Selenium, and Carotenoids. Washington (DC): National Academies Press (US). 
[37] Levine M, Wang Y, Padayatty SJ and Morrow J. (2001). A new recommended dietary allowance of vitamin C for healthy young women. Proceedings of National Academy of Sciences of the United States of America, 98(17), 9842-6.

[38] Frei B, Birlouez I and Lykkesfeldt J. (2012). What is the optimum intake of vitamin C in humans? Critical Reviews in Food Science and Nutrition, 52, 815-29.

[39] Carr AC. (2020). A new clinical trial to test high-dose vitamin C in patients with COVID-19. Critical Care, 24(1), 133.

[40] Aranow C. (2011). Vitamin D and the immune system. Journal of Investigative Medicine, 59(6), 881-6.

[41] Watkins RR, Lemonovich TL and Salata RA. (2015). An update on the association of vitamin D deficiency with common infectious diseases. Canadian Journal of Physiology and Pharmacology, 93(5), 363-8.

[42] Asbaghi O, Sadeghian M, Mozaffari-Khosravi H, Maleki V, Shokri A, Hajizadeh-Sharafabad F, Alizadeh, M and Sadeghi 0. (2020). The effect of vitamin d-calcium co-supplementation on inflammatory biomarkers: A systematic review and meta-analysis of randomized controlled trials. Cytokine, 129, 155050.

[43] Institute of Medicine (US) Committee to Review Dietary Reference Intakes for Vitamin D and Calcium, Ross AC, Taylor CL, Yaktine AL, Del Valle HB, eds. (2011). Dietary Reference Intakes for Calcium and Vitamin D. Washington (DC): National Academies Press (US), 2011.

[44] Aloia JF. (2011). Clinical Review: The 2011 report on dietary reference intake for vitamin D: where do we go from here? The Journal of Clinical Endocrinology and Metabolism, 96(10), 2987-96.

[45] Tangpricha V, Pearce EN, Chen TC and Holick MF. (2002). Vitamin D in- sufficiency among free-living healthy young adults. American Jornal of Medicine, 112, 659-662.

[46] Holick MF. (2004). Sunlight and vitamin D for bone health and prevention of autoimmune diseases, cancers, and cardiovascular disease. American Journal of Clinical Nutrition 80, 1678S-1688S.

[47] Taylor PN and Davies JS. (2018). A review of the growing risk of vitamin D toxicity from inappropriate practice. British Journal of Clinical Pharmacology, 84(6), 1121-1127.

[48] Galior K, Grebe S and Singh R. (2018). Development of Vitamin D Toxicity from Overcorrection of Vitamin D Deficiency: A Review of Case Reports. Nutrients, 10(8), 953.

[49] Colombo ML. (2010). An update on vitamin E, tocopherol and tocotrienol-perspectives. Molecules, 15(4), 21032113.

[50] Jiang Q. (2014). Natural forms of vitamin E: metabolism, antioxidant, and anti-inflammatory activities and their role in disease prevention and therapy. Free Radical Biology \& Medicine, 72, 76-90.

[51] Clarke MW, Burnett JR and Croft KD. (2008). Vitamin E in human health and disease. Critical Reviews in Clinical Laboratory Science, 45(5), 417-450.

[52] Roghani M and Behzadi G. (2001). Neuroprotective effect of vitamin E on the early model of Parkinson's disease in rat: behavioral and histochemical evidence. Brain Research, 892(1), 211-217.

[53] Cherubini A, Martin A, Andres-Lacueva C, Di Iorio A, Lamponi M, Mecocci P, Bartali B, Corsi A, Senin U and Ferrucci L. (2005). Vitamin E levels, cognitive impairment and dementia in older persons: the InCHIANTI study. Neurobiology of Aging, 26(7), 987-994.

[54] Beharka A, Redican S, Leka L and Meydani SN. (1997). Vitamin E status and immune function. Methods in Enzymology, 282, 247-263.

[55] Eskew ML, Scholz RW, Reddy CC, Todhunter DA and Zarkower A. (1985). Effects of vitamin E and selenium deficiencies on rat immune function. Immunology 54, 173-180.

[56] Coquette A, Vray B and Vanderpas J. (1986). Role of vitamin E in the protection of the resident macrophage membrane against oxidative damage. Archives internationales de physiologie et de biochimie, 94, S29-S34.

[57] Han SN and Meydani SN. (2006). Impact of vitamin E on immune function and its clinical implications. Expert Review of Clinical Immunology, 2, 561-567.

[58] Tengerdy RP, Henzerling RH, Brown GL and Mathias MM. (1973). Enhancement of the humoral immune response by vitamin E. International Archives of Allergy and Applied Immunology, 44, 221-232. 
[59] Meydani SN, Barklund MP, Liu S, Meydani M, Miller RA, Cannon JG, Morrow FD, Rocklin R and Blumberg JB. (1990). Vitamin E supplementation enhances cell-mediated immunity in healthy elderly subjects. American Journal of Clinical Nutrition, 52, 557-563.

[60] Meydani SN, Meydani M, Blumberg JB, Leka LS, Siber G, Loszewski R, Thompson C, Pedrosa MC, Diamond RD and Stollar BD. (1997). Vitamin E supplementation and in vivo immune response in healthy elderly subjects a randomized controlled trial. The Journal of American Medical Association, 277, 1380-1386.

[61] Wu D and Meydani SN. (2008). Age-associated changes in immune and inflammatory responses: impact of vitamin E intervention. Journal of Leukocyte Biology, 84, 900-914.

[62] Moriguchi S, Miwa H, Okamura M, Maekawa K, Kishino Y and Maeda K. (1993). Vitamin E is an important factor in $t$ cell differentiation in thymus of f344 rats. Journal of Nutrition Science and Vitaminology, 39, 451-463.

[63] Meydani SN, Meydani M, Verdon CP, Shapiro AA, Blumberg JB and Hayes KC. (1986). Vitamin E supplementation suppresses prostaglandin e1(2) synthesis and enhances the immune response of aged mice. Mechanisms of Ageing and Development, 34, 191-201.

[64] Corwin LM and Shloss J. (1980). Influence of vitamin E on the fitogeni response of murine lymphoid cells. Journal of Nutrition. 110, 916-923.

[65] Wang Y and Watson RR. (1994) Vitamin E supplementation at various levels alters cytokine production by thymocytes during retrovirus infection causing murine aids. Thymus, 22, 153-165.

[66] Miller ME. (1979). Phagocytic function in the same neonate: selected aspects. Pediatrics, 64, 5709-5712.

[67] Baehner RL, Boxer LA, Allen JM and Davis J. (1977). Autooxidation as a basis for altered function by polymorphonuclear leukocytes. Blood, 50, 327-335.

[68] Prasad JS. (1980). Effect of vitamin E supplementation on leukocyte function. American Journal of Clinical Nutrition, 33, 606-608.

[69] De la Fuente M, Hernanz A, Guayerbas N, Victor VM and Arnalich F. (2008). Vitamin E ingestion improves several immune functions in elderly men and women. Free Radical Research, 42, 272-280.

[70] Neupane B, Walter SD, Krueger P, Marrie T and Loeb M. (2010). Predictors of inhospital mortality and rehospitalization in older adults with community acquired pneumonia: a prospective cohort study. BMC Geriatriatrics, 10, 22.

[71] Meydani SN, Leka LS, Fine BC, Dallal GE, Keusch GT, Singh MF and Hamer DH. (2004). Vitamin E and respiratory tract infections in elderly nursing home residents: a randomized controlled trial. The Journal of American Medical Association, 292(7), 828-836.

[72] Graat JM, Schouten EG and Kok FJ. (2002). Effect of daily vitamin E and multivitamin-mineral supplementation on acute respiratory tract infections in elderly persons: a randomized controlled trial. The Journal of American Medical Association, 288, 715-721.

[73] Hemila H. (2016). Vitamin E administration may decrease the incidence of pneumonia in elderly males. Clinical Interventions in Aging, 11, 1379-1385.

[74] Hemila H, Virtamo J, Albanes D and Kaprio J. (2006). The effect of vitamin E on common cold incidence is modified by age, smoking and residential neighborhood. Journal of the American College of Nutrition, 25, 332-339.

[75] Mocchegiani E, Costarelli L, Giacconi R, Malavolta M, Basso A, Piacenza F, Ostan R, Cevenini E, Gonos ES, Franceschi C and Monti D. (2014). Vitamin E-gene interactions in aging and inflammatory agerelated diseases: implications for treatment. A systematic review. Ageing Research Reviews, 14, 81-101.

[76] Kowdley KV, Mason JB, Meydani SN, Cornwall S and Grand RJ. (1992). Vitamin E deficiency and impaired cellular immunity related to intestinal fat malabsorption. Gastroenterology, 102, 2139-2142.

[77] Traber GM and Sies H. (1996). Vitamin E in humans: demand and delivery. Annual Review of Nutrition, 6, 32147.

[78] Muller DP and Goss-Sampson MA. (1990). Neurochemical, neurophysiological, and neuropathological studies in vitamin E deficiency. Critical Reviews in Neurobiology, 5(3), 239-63.

[79] Piroddi M, Albini A, Fabiani R, Giovannelli L, Luceri C, Natella F, Rosignoli P, Rossi T, Taticchi A, Servili M and Galli F . (2017). Nutrigenomics of extra-virgin olive oil: A review. Biofactors, 43(1), 17-41. 
[80] Traber MG and Manor D. (2012). Vitamin E. Advances in Nutrition, 3(3), 330-331.

[81] EFSA NDA Panel (EFSA Panel on Dietetic Products, Nutrition and Allergies. (2015). Scientific Opinion on Dietary Reference Values for vitamin E as $\alpha$-tocopherol. European Food Safety Authority Journal, 13(7), 4149, 72.

[82] Bates CJ. (1995). Vitamin A. Lancet, 345(8941), 31-35.

[83] Ross AC and Ternus ME. (1993). Vitamin A as a hormone: recent advances in understanding the actions of retinol, retinoic acid, and beta carotene. Journal of the American Dietetic Association, 93(11), 1285-1292.

[84] Harrison EH and Curley RW Jr. (2016). Carotenoids and Retinoids: Nomenclature, Chemistry, and Analysis. Subcell Biochem, 81, 1-19.

[85] Belyaeva OV, Adams MK, Popov KM and Kedishvili NY. (2019). Generation of Retinaldehyde for Retinoic Acid Biosynthesis. Biomolecules, 10(1), 5.

[86] Ott DB and Lachance PA. (1979). Retinoic acid--a review. American Journal of Clinical Nutrition, 32(12), 25222531.

[87] Kedishvili NY. (2016). Retinoic Acid Synthesis and Degradation. Subcellular Biochemistry, 81, 127-161.

[88] Clagett-Dame M and Knutson D. (2011). Vitamin A in reproduction and development. Nutrients, 3, 385-428.

[89] Chen W and Chen G. (2014). The Roles of Vitamin A in the Regulation of Carbohydrate, Lipid, and Protein Metabolism. Journal of Clinical Medicine, 3(2), 453-79.

[90] Conaway HH, Henning P and Lerner UH. (2013). Vitamin a metabolism, action, and role in skeletal homeostasis. Endocrine Reviews, 34(6), 766-97.

[91] Shearer KD, Stoney PN, Morgan PJ and McCaffery PJ. (2012). A vitamin for the brain. Trends in Neurosciences, 35(12), 733-41

[92] Zhong M, Kawaguchi R, Kassai M and Sun H. (2012). Retina, retinol, retinal and the natural history of vitamin A as a light sensor. Nutrients, 4(12), 2069-96.

[93] Eggersdorfer M and Wyss A. (2018). Carotenoids in human nutrition and health. Archives of Biochemistry and Biophysics, 652, 18-26.

[94] Larange A and Cheroutre H. (2016). Retinoic Acid and Retinoic Acid Receptors as Pleiotropic Modulators of the Immune System. Annual Review of Immunology, 34, 369-94.

[95] Brown CC and Noelle RJ. (2015).Seeing through the dark: New insights into the immune regulatory functions of vitamin A. European Journal of Immunology, 45(5), 1287-95.

[96] Huang Z, Liu Y, Qi G, Brand D and Zheng SG. (2018). Role of Vitamin A in the Immune System. Journal of Clinical Medicine, 7(9), 258.

[97] Ross AC. (2012). Vitamin A and retinoic acid in T cell-related immunity. American Journal of Clinical Nutrition, 96(5), 1166S-72S.

[98] Stephensen CB. (2001). Vitamin A, infection, and immune function. Annual Review of Nutrition, 21, 167-92.

[99] Bono MR, Tejon G, Flores-Santibañez F, Fernandez D, Rosemblatt M and Sauma D. (2016). Retinoic Acid as a Modulator of T Cell Immunity. Nutrients, 8(6), 349.

[100] Xiao S, Jin H, Korn T, Liu SM, Oukka M, Lim B and Kuchroo vK. (2008). Retinoic acid increases Foxp3+ regulatory T cells and inhibits development of Th17 cells by enhancing TGF-beta-driven Smad3 signaling and inhibiting IL6 and IL-23 receptor expression. Journal of Immunology, 181(4), 2277-2284.

[101] Penkert RR, Jones BG, Häcker H, Partridge JF and Hurwitz JL. (2017). Vitamin A differentially regulates cytokine expression in respiratory epithelial and macrophage cell lines. Cytokine, 91, 1-5.

[102] Mora JR, Iwata M and von Andrian UH. (2008). Vitamin effects on the immune system: vitamins A and D take centre stage. Nature Reviews Immunolology, 8(9), 685-698.

[103] Cassani B, Villablanca EJ, De Calisto J, Wang S and Mora JR. (2012). Vitamin A and immune regulation: role of retinoic acid in gut-associated dendritic cell education, immune protection and tolerance. Molecular Aspects of Medicine, 33(1), 63-76.

[104] Villamor E and Fawzi WW. (2005). Effects of vitamin a supplementation on immune responses and correlation with clinical outcomes. Clinical Microbiology Reviews, 18(3), 446-464. 
[105] Sommer A, Djunaedi E, Loeden AA, Tarwotjo I, West K JR, Tilden R and Mele L. (1986). Impact of Vitamin A supplementation on childhood mortality. Lancet, 327, 1169-1173.

[106] Semba RD. (1999). Vitamin A and immunity to viral, bacterial and protozoan infections. Proceedings of the Nutrition Society, 58, 719-27.

[107] Villamor E, Mbise R, Spiegelman D, Hertzmark E, Fataki M, Peterson KE, Ndossi G and Fawzi WW. (2002). Vitamin A supplements ameliorate the adverse effect of HIV-1, malaria, and diarrheal infections on child growth. Pediatrics, 109, (1)e6.

[108] Semba RD. (1999). Vitamin A as “Anti-Infective” Therapy, 1920-1940. Journal of Nutrition, 129(4), 783-791.

[109] Office of Dietary Supplements, National Institutes of Health. (2017). Vitamin A.

[110] Zinder R, Cooley R, Vlad LG and Molnar JA. Vitamin A and Wound Healing. Nutrition in Clinical Practice, 34(6), 839-849.

[111] Institute of Medicine (US) Panel on Micronutrients. (2001). Dietary Reference Intakes for Vitamin A, Vitamin K, Arsenic, Boron, Chromium, Copper, Iodine, Iron, Manganese, Molybdenum, Nickel, Silicon, Vanadium, and Zinc. Washington (DC): National Academies Press (US), 4, 82.

[112] Ross AC (2010). Diet in Vitamin A Research. Methods in Molecular Biology.

[113] Xavier AA and Pérez-Gálvez A. (2016) Carotenoids as a Source of Antioxidants in the Diet. Subcellular Biochemistry, 79, 359-75.

[114] Hamishehkar H, Ranjdoost F, Asgharian P, Mahmoodpoor A and Sanaie S. (2016). Vitamins, Are They Safe? Advanced Pharmaceutical Bullettin, 6(4), 467-477.

[115] Penniston KL and Tanumihardjo SA. (2006). The acute and chronic toxic effects of vitamin A. American Journal of Clinical Nutrition, 83(2), 191-201.

[116] Jee J, Hoet AE, Azevedo MP, Vlasova AN, Loerch SC, Pickworth CL, Hanson J and Saif LJ. (2013). Effects of dietary vitamin A content on antibody responses of feedlot calves inoculated intramuscularly with an inactivated bovine coronavirus vaccine. American Journal of Veterinary Research, 74, 1353-1362.

[117] West CE, Sijtsma SR, Kouwenhoven B, Rombout JH and van der Zijpp AJ. (1992). Epithelia-damaging virus infections affect vitamin A status in chickens. Journal of Nutrition, 122, 333-339.

[118] Depeint F, Bruce WR, Shangari N, Mehta R and O'Brien PJ. (2006). Mitochondrial function and toxicity: role of the B vitamin family on mitochondrial energy metabolism. Chemico-Biological Interactions, 163(1-2), 94-112.

[119] Mikkelsen K and Apostolopoulos V. (2018). B Vitamins and Ageing. Subcellular Biochemistry, 90, 451-470.

[120] Young LM, Pipingas A, White DJ, Gauci S and Scholey A. (2019). A Systematic Review and Meta-Analysis of B Vitamin Supplementation on Depressive Symptoms, Anxiety, and Stress: Effects on Healthy and 'At-Risk' Individuals. Nutrients, 11(9), 2232.

[121] Axelrod AE. (1981). Role of the B vitamins in the immune response. Advances in Experimental Medicine and Biology, 135, 93-106.

[122] Wintergerst ES, Maggini S and Hornig DH. (2007). Contribution of selected vitamins and trace elements to immune function. Annals of Nutrition and Metabolism, 51(4), 301-323.

[123] Tamura J, Kubota K, Murakami H, Sawamura M, Matsushima T, Tamura T, Saitoh T, Kurabayshi H and Naruse T. (1999). Immunomodulation by vitamin B12: augmentation of CD8+ T lymphocytes and natural killer (NK) cell activity in vitamin B12-deficient patients by methyl-B12 treatment. Clinical \& Experimental Immunology, 116(1), 28-32.

[124] Doke S, Inagaki N, Hayakawa T and Tsuge H. (1998). Effects of vitamin B6 deficiency on cytokine levels and lymphocytes in mice. Bioscience, Biotechnology, and Biochemistry, 62(5), 1008-1010.

[125] Qian B, Shen S, Zhang J and Jing P. (2017). Effects of vitamin B6 deficiency on the composition and functional potential of T cell populations. Journal of Immunology Research, 20172197975.

[126] Partearroyo T, Úbeda N, Montero A, Achón M and Varela-Moreiras G. (2013). Vitamin B(12) and folic acid imbalance modifies NK cytotoxicity, lymphocytes B and lymphoprolipheration in aged rats. Nutrients, 5(12), 4836-4848. 
[127] Doke S, Inagaki N, Hayakawa T and Tsuge H. (1997). Effect of vitamin B6 deficiency on an antibody production in mice. Bioscience, Biotechnology, and Biochemistry, 61(8), 1331-1336.

[128] Chandra RK, Heresi G and Au B. (1980). Serum thymic factor activity in deficiencies of calories, zinc, vitamin A and pyridoxine. Clinical \& Experimental Immunology, 42(2), 332-335.

[129] Qian B, Shen S, Zhang J and Jing P. (2017). Effects of Vitamin B6 Deficiency on the Composition and Functional Potential of T Cell Populations. Journal of Immunology Research, 2197975.

[130] Friso S, Jacques PF, Wilson PW, Rosenberg IH and Selhub J. (2001). Low circulating vitamin B 6 is associated with elevation of the inflammation marker C-reactive protein independently of plasma homocysteine levels. Circulation, 103, 2788-2791.

[131] Friso S, Girelli D, Martinelli N, Olivieri O, Lotto V, Bozzini C, Pizzolo F, Faccini G, Beltrame F and Corrocher R. (2004). Low plasma vitamin B-6 concentrations and modulation of coronary artery disease risk. American Journal of Clinical Nutrition, 79, 992-998.

[132] Courtemanch, C, Elson-Schwab I, Mashiyama ST, Kerry N and Ames BN. (2004). Folate deficiency inhibits the proliferation of primary human CD8+ T lymphocytes in vitro. Journal of Immunology, 173(5), 3186-3192.

[133] Wu CH, Huang TC and Lin BF. (2017). Folate deficiency affects dendritic cell function and subsequent T helper cell differentiation. The Journal of Nutritional Biochemistry, 41, 65-72.

[134] Shane B. (2008). Folate and vitamin B12 metabolism: overview and interaction with riboflavin, vitamin B6, and polymorphisms. Food and Nutrition Bullettin, 29(2 Suppl), S5-S19.

[135] Troen AM, Mitchell B, Sorensen B, Wener MH, Johnston A, Wood B, Selhub J, McTiernan A, Yasui Y, Oral E, Potter JD and Ulrich CM. (2006). Unmetabolized folic acid in plasma is associated with reduced natural killer cell cytotoxicity among post- menopausal women. Journal of Nutrition, 136(1), 189-194.

[136] Planells E, Sánchez C, Montellano MA, Mataix J and Llopis J. (2003). Vitamins B6 and B12 and folate status in an adult Mediterranean population. European Journal of Clinical Nutrition, 57(6), 777-785.

[137] Morris MS, Picciano MF, Jacques PF and Selhub J. (2003). Plasma pyridoxal 5'-phosphate in the US population: the National Health and Nutrition Examination Survey, 2003-2004. American Journal of Clinical Nutrition, 87(5), 1446-1454.

[138] McLean E, de Benoist B and Allen LH. (2008). Review of the magnitude of folate and vitamin B12 deficiencies worldwide. Food and Nutrition Bullettin, 29(2) (Suppl.), S38-S51.

[139] Wong CW. (2015). Vitamin B12 deficiency in the elderly: is it worth screening? Hong Kong Medical Journal, 21(2), 155-164.

[140] Dhonukshe-Rutten RAM, de Vries JHM, de Bree A, van der Put N, van Staveren WA and de Groot LC. (2009). Dietary intake and status of folate and vitamin B12 and their association with homocysteine and cardiovascular disease in European populations. European Journal of Clinical Nutrition, 63(1), 18-30.

[141] Pawlak R. (2015). Is vitamin B12 deficiency a risk factor for cardiovascu- lar disease in vegetarians? American Journal of Preventive Medicine, 48(6), e11-e26.

[142] Kjeldby IK, Fosnes GS, Ligaarden SC and Farup PG. (2013). Vitamin B6 deficiency and diseases in elderly people-a study in nursing homes. BMC Geriatrics, 13, 13.

[143] Keil SD, Bowen R and Marschner S. (2016). Inactivation of Middle East respiratory syndrome coronavirus (MERS$\mathrm{CoV}$ ) in plasma products using a riboflavin-based and ultraviolet light-based photochemical treatment. Transfusion, 56, 2948-2952.

[144] Kyme P, Thoennissen NH, Tseng CW, Thoennissen GB, Wolf AJ, Shimada K, Krug UO, Lee K, Müller-Tidow C, Berdel WE, Hardy WD, Gombart AF, Koeffler HP and Liu GY. (2012). C/EBPepsilon mediates nicotinamideenhanced clearance of Staphylococcus aureus in mice. Journal of Clinical Investigation, 122, 3316-3329.

[145] Sankar MJ, Chandrasekaran A, Kumar P, Thukral A, Agarwal R and Paul VK. (2016). Vitamin K prophylaxis for prevention of vitamin K deficiency bleeding: a systematic review. Journal of Perinatology, 36 Suppl 1(Suppl 1), S29-S35.

[146] Shearer MJ, Fu X and Booth SL. (2012). Vitamin K nutrition, metabolism, and requirements: current concepts and future research. Advances in Nutrition, 3(2), 182-195. 
[147] Verhoef TI, Redekop WK, Daly AK, van Schie RM, de Boer A and Maitland-van der Zee AH. (2014). Pharmacogenetic-guided dosing of coumarin anticoagulants: algorithms for warfarin, acenocoumarol and phenprocoumon. British Journal of Clinical Pharmacology, 77(4), 626-641.

[148] Witt DM, Nieuwlaat R, Clark NP, Ansell J, Holbrook A, Skov J, Shehab N, Mock J, Myers T, Dentali F, Crowther MA, Agarwal A, Bhatt M, Khatib R, Riva JJ, Zhang Y and Guyatt G. (2018). American Society of Hematology 2018 guidelines for management of venous thromboembolism: optimal management of anticoagulation therapy. Blood Advances, 2(22), 3257-3291.

[149] Barcellona D, Fenu L and Marongiu F. (2017). Point-of-care testing INR: an overview. Clin Chem Lab Med, 55(6), 800-805.

[150] Booth SL. (2012). Vitamin K: food composition and dietary intakes. Food \& Nutrition Research, 56.

[151] Trumbo P, Yates AA, Schlicker S and Poos M. (2001). Dietary reference intakes: vitamin A, vitamin K, arsenic, boron, chromium, copper, iodine, iron, manganese, molybdenum, nickel, silicon, vanadium, and zinc. Journal of American Dietetic Association, 101(3), 294-301.

\section{How to cite this article}

Carella AM, Benvenuto A, Lagattolla V, Marinelli T, De Luca P, Ciavarrella G, Modola G, Di Pumpo M, Ponziano E and Benvenuto M. (2020). Vitamin supplements in the Era of SARS-Cov2 pandemic. GSC Biological and Pharmaceutical Sciences, 11(2), 07-19. 